\title{
Increased Activity of Adenine Phosphoribosyltransferase in Erythrocytes of Normal Newborn Infants
}

\author{
Margaret Borden, William L. Nyhan, ${ }^{[23]}$ and Bohdan Bakay \\ Department of Pediatrics, University of California, San Diego, La Jolla, California, USA
}

\begin{abstract}
Extract
Transient elevation of the activity of adenine phosphoribosyltransferase (APRT) was found along with hyperuricemia in an infant in the neonatal period. A systematic investigation was begun of the activity of the phosphoribosyltransferases in the first days of life. Adenine phosphoribosyltransferase and hypoxanthine guanine phosphoribosyltransferase (HGPRT) were assayed using radiochemical methods in which the nucleotide products of the enzymatic reactions are precipitated with lanthanum chloride. Phosphoribosyl pyrophosphate (PRPP) was assayed using a method based on the utilization of PRPP in a system containing $\left({ }^{14} \mathrm{C}\right)$ adenine and APRT. The activity of APRT in the neonate was found to exceed consistently that of the adult. The degree of elevation was as great as that observed in patients with Lesch-Nyhan syndrome. The mean value of APRT in the adult was $665 \mathrm{nmol}$ AMP $/ \mathrm{min} / \mathrm{ml}$ packed cells, whereas in the neonate the mean value was 1,150 . The difference between neonate and adult was significant statistically at the $<0.001$ level.

Erythrocytes of adults were fractionated into young and old cells. The activity of APRT in the young cells from each individual was 1.5-2.1 times that of the old cells. The concentrations of PRPP were significantly greater in the erythrocytes of neonates than in those of adults $(P<0.001)$. The mean concentration in the infants was 2.4 times the adult mean value.

It was concluded that the elevated activity of APRT in the neonate reflected partly a young population of cells and partly a stabilization by PRPP of APRT against the attrition of aging.
\end{abstract}

\section{Speculation}

The activity of APRT was first found to be elevated in the erythrocytes of patients with the Lesch-Nyhan syndrome. It has been found to be elevated to an identical degree in patients with partial deficiency of HGPRT and with overproduction of uric acid without abnormality in HGPRT. Now it is apparent that APRT is elevated to precisely the same degree in the normal newborn infant. These observations speak for a common mechanism of biologic control. 


\section{Introduction}

Adenine phosphoribosyltransferase (adenylate:pyrophosphate phosphoribosyltransferase EC. 2.4.2.7) catalyzes the conversion of adenine to its nucleotide, AMP. The activity of this enzyme is elevated in the erythrocytes of patients with the Lesch-Nyhan syndrome, in which the activity of HGPRT (IMP: purophosphate phosphoribosyltransferase EC. 2.4.2.8) is virtually absent $[4,17,18,20]$. Adenine phosphoribosyltransferase activity is also increased in patients with partial deficiency of HGPRT [10, 11]. The activity of this enzyme may also be increased in patients in whom there is hyperuricemia and an overproduction of purine de novo and no abnormality in HGPRT [14]. Therefore, we regularly examine the blood for APRT as well as HGPRT activity in patients found to have large amounts of uric acid in the blood and urine.

This investigation was begun after observations on a very young infant who was found to have elevated concentrations of uric acid in body fluids and elevated activity of APRT in the erythrocytes with normal activity of HGPRT. By the time another sample of blood could be obtained to pursue these findings the hyperuricemia had disappeared and the activity of APRT was normal. These observations suggested that there might be developmental changes in APRT in the first days of life. Therefore, a systematic investigation was begun of the activity of the purine phosphoribosyltransferases in the newborn infant. It is clear that the establishment of normal values in the neonate is a prerequisite for the early detection of disorders of purine metabolism.

\section{Materials and Methods}

Venous blood was collected from healthy adults and from normal newborn infants in the first week of life in tubes which contained heparin. Data were obtained for comparison on patients with the Lesch-Nyhan syndrome. Assays of APRT and HGPRT were made using the radiochemical method of Bakay et al. [4] in which the product of the reaction, AMP or IMP, is precipitated with lanthanum chloride.

Assays of HGPRT and APRT were also made after separation by polyacrylamide gel electrophoresis as described previously $[1,2]$. In order to maintain the precise timing that would permit their use as quantitative assay of enzyme activity, the gels were cooled in an ice water bath immediately after electrophoresis. Icecold substrate was added, and the reaction was permitted to proceed at $37^{\circ}$ for $30 \mathrm{~min}$. Thereafter the tubes were placed in an ice water bath and cold lanthanum chloride solution was added 5 min later. After the gels were washed in water, they were fractionated in a mechanical fractionator. Measurement of radioactivity in the gel was performed in a scintillation spectrometer equipped with a digital printer as well as a chart recorder. The efficiency of counting of ${ }^{14} \mathrm{C}$, as determined using an internal standard, was $74 \%$.

Concentrations of PRPP were also measured in neonates and adults. The assay was based on the utilization of PRPP in a system containing $\left({ }^{14} \mathrm{C}\right)$ adenine. The incubation was carried out in $0.1 \mathrm{M}$ Tris- $\mathrm{HCl}$ buffer containing $0.01 \mathrm{M} \mathrm{MgSO}_{4}$ and $0.2 \mathrm{ml}$ whole blood in a final volume of $1.5 \mathrm{ml}$.

For this assay blood was drawn into heparinized tubes, placed on ice, and the assay started immediately. Blank and test samples were set up in duplicate in counting vials standing on ice. The vials were then capped, swirled, and placed in a $37^{\circ}$ metabolic shaker bath for $20 \mathrm{~min}$. After incubation, $4 \mathrm{ml} 0.4 \mathrm{~N} \mathrm{HCl}$ were added to each vial.

Aliquots were then applied to Dowex columns according to the method of Sweetman et al. [21] for chromatographic analysis of purines. Fractions of approximately $7 \mathrm{ml}$ were collected and an aliquot of each counted in a scintillation counter. Detectable activity was found only in the ATP and ADP in the usual blood sample. In samples with extremely elevated concentrations of PRPP activity was also found in the AMP area. Peak areas were calculated and corrected to disintegrations per minute per milliliter of whole blood. Hematocrits were determined on each blood sample.

Erythrocytes of normal adults were separated into young and old cells by sedimentation [5]. Aliquots of $10 \mu \mathrm{l}$ were taken in triplicate from each sampling and assayed directly for APRT activity or lysed in 19 or 39 volumes of cold water in samples to be assayed by electrophoresis.

\section{Results}

\section{APRT Activity in Neonates}

Comparison of the activities of APRT in the erythrocytes of newborn infants and adults is shown in Figure 1. In the neonate the activity of APRT was found consistently to be elevated. The degree of elevation was as great as that observed in patients with the Lesch-Nyhan syndrome. The mean value of APRT in the adult was $665 \mathrm{nmol} \mathrm{AMP} / \mathrm{min} / \mathrm{ml}$ packed cells 


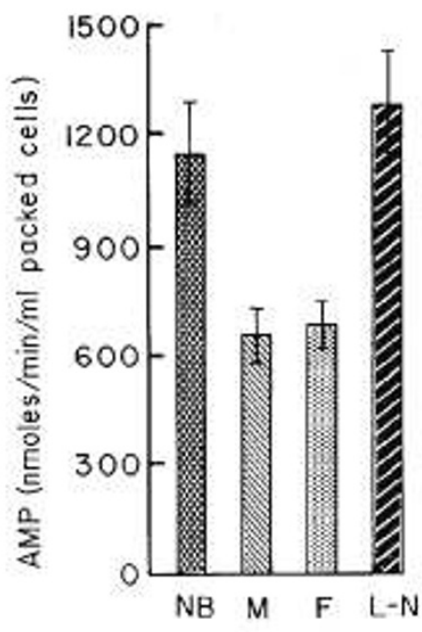

Fig. 1. Activity of APRT in erythrocytes of normal neonates and adults. $N B$ : newborn; $M$ : adult male; $F$ : adult female; $L-N$ : patients with the Lesch-Nyhan syndrome. The bars represent mean activities and the bracketed lines the SD. The numbers of subjects were 13 infants, 13 adults, and 6 patients with the Lesch-Nyhan syndrome.

and the so was 67. Among adults there was no significant difference between males and females.

The mean value for APRT in the neonate was 1,150 $\mathrm{nmol} \mathrm{AMP} / \mathrm{min} / \mathrm{ml}$ packed cells and the sD was 140 . The difference between neonate and adult was found to be highly significant statistically $(t=10.79, P<$ $0.001)$. The difference between the adult mean and that of patients with the Lesch-Nyhan syndrome was also highly significant $(t=11.77, P<0.001)$. The means of the normal neonates and the patients with the Lesch-Nyhan syndrome did not differ significantly.

In contrast to the data on APRT the activity of HGPRT was not different in populations of erythrocytes from neonates and from adults. The mean in the adult was $1,269 \mathrm{nmol} \mathrm{IMP} / \mathrm{min} / \mathrm{ml}$ packed cells, whereas that in the neonate was $1,196 \mathrm{nmol}$ IMP/ $\mathrm{min} / \mathrm{ml}$ packed cells.

\section{APRT in Young and Old Cells}

The activity of APRT in young and old erythrocytes derived from the blood of adults is shown in Figure 2. The young cells always had greater APRT activity than the older cells. The APRT of the old cells ranged from 374 to $512 \mathrm{nmol} \mathrm{AMP} / \mathrm{min} / \mathrm{ml}$ packed cells, whereas the activity of the young cells from each individual was 1.5-2.1 times that of old cells. Both young and old cells from females were slightly higher in activity than those from males.

Similar observations were made using the electro- phoretic method. In Figure 3 the areas under the APRT were measured by a planimeter and expressed in terms of square centimeters per peak produced by 1 $\mu l$ packed cells. The activity in the young cells was 1.7 times that found in the old cells. The value for the

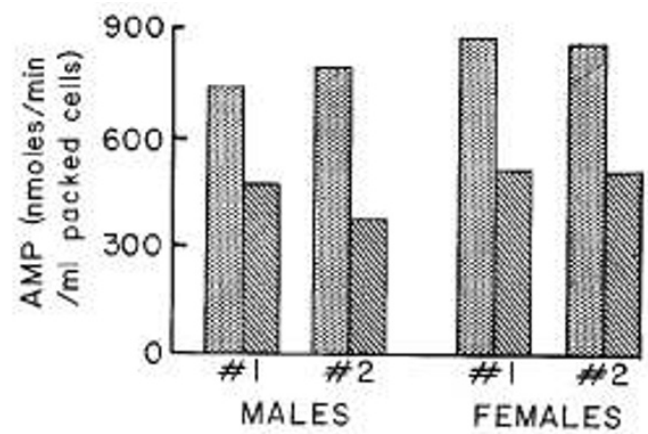

Fig. 2. Activity of adenine phosphoribosyltransferase in young and old erythrocytes of four normal adults. In each instance the stippled bar to the left represents the young cells.

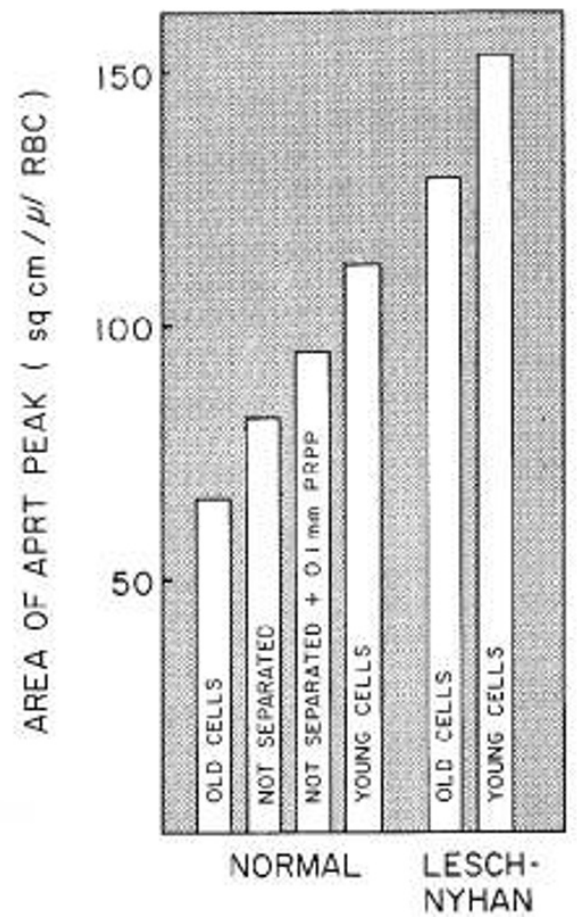

Fig. 3. Activity of adenine phosphoribosyltransferase $(A P R T)$ in fractionated and unfractionated erythrocytes of normal adults and patients with the Lesch-Nyhan syndrome. Hemolysates were prepared from young and old and from unfractionated cells of three normal individuals. Fractionation was also carried out in three patients with the Lesch-Nyhan syndrome. Hemolysates were electrophoresed on polyacrylamide gel and developed for APRT. The activity was determined by measuring the area of the APRT peak with a planimeter. The data shown are the means. PRPP: phosphoribosyl pyrophosphate; $R B C$ : red blood cells. 
unseparated cells of these normal adults was closer to that of the old cells, approximating 1.3 times the mean for the old cells. In this system the activity of APRT in patients with the Lesch-Nyhan syndrome was 1.8 times that of the normal unfractionated adult cell. This figure is quite comparable to the difference shown in Figure 1, in which the ratio of patient to adult control was of the order of 1.9 times. Supplementation of the adult cells with PRPP increased the activity of APRT considerably, but not to the level found in the fractionated young cells.

The difference between the APRT activity of young and old cells was observed at three different dilutions of hemolysate, and in neither the young nor the old

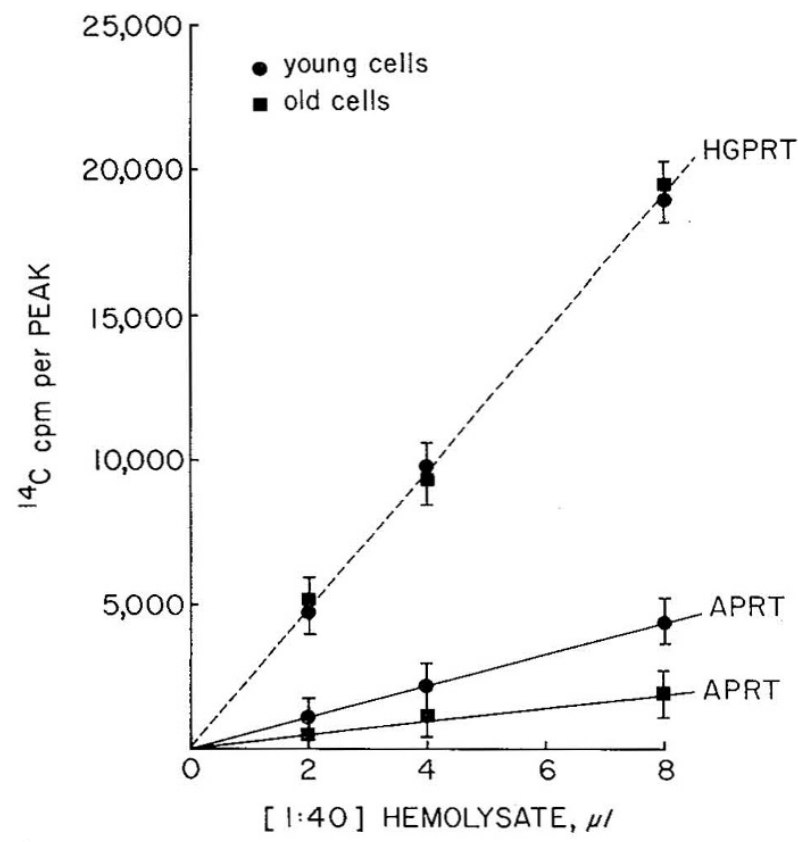

Fig. 4. Activity of adenine phosphoribosyltransferase (APRT) and hypoxanthine guanine phosphoribosyltransferase (HGPRT) in young and old erythrocytes of blood from adults. Three different aliquots of $1 / 40$ hemolysate were prepared from cells and separated by density centrifugation, after which they were subjected to electrophoretic separation on polyacrylamide gel.

Table I. Concentrations of phosphoribosyl pyrophosphate in erythrocytes of adults and newborn infants ${ }^{1}$

\begin{tabular}{cccc}
\hline Subject & No. & $\begin{array}{c}\text { Mean, nmol/ml } \\
\text { packed cells }\end{array}$ & sD \\
\hline Adults & 7 & 5.72 & 0.8647 \\
Infants & 12 & 13.17 & 2.343 \\
\hline
\end{tabular}

${ }^{1}$ The means were compared using the $t$ test; the value for $t$ was $7.66(P<0.001)$. did the plot depart from linearity (Fig. 4). The activity of HGPRT was identical in both cell populations.

The concentrations of PRPP found in the blood of adults and of newborn infants are shown in Table I. The concentrations in the infants were significantly greater than those in the adult $(P<0.001)$. The mean concentration in the infants was 2.4 times the adult mean value.

\section{Discussion}

The data obtained in this study indicate that the activity of APRT in the erythrocytes of the human newborn infant is significantly greater than that of the adult. The values obtained in the infants were comparable to those of patients with the Lesch-Nyhan syndrome. The greater activity of APRT in the neonate was not due to the presence of small or large molecules in the hemolysate, as it was also demonstrated when the enzyme was separated from other molecules by electrophoresis.

A similar difference was found between the activities of young and old erythrocytes fractionated from the blood of adults. This is consistent with the concept that the erythrocyte population of the neonate contains a larger proportion of young cells [15]. Similarly, the activity of glucose 6-phosphate dehydrogenase is greater in the neonate than in the mother, and greater in the young cells than in the old cells of the blood of adults [3].

The activities of a number of enzymes have been found to be higher in erythrocytes from neonates than from adults [12]. However, these changes do not all correlate well with the age of the erythrocyte. Glucose 6-phosphate dehydrogenase, hexokinase, and pyruvate kinase were found to be about as high in the blood of adults with hemolytic anemias as they were in the neonate, and reticulocyte counts were also comparable. Four other enzymes were found to have significantly higher activities in the neonate than in adults with reticulocytosis. Four enzymes, including adenylate kinase, were found to have lower activities in the neonate than in adults with or without reticulocytosis [12]. Thus, there are many differences in enzyme activity between erythrocytes from neonates and from adults, some of which appear to be related to the age of the cell.

It is likely that each enzyme protein has a unique biologic half-life. Some very stable proteins may not change at all as the cell ages. Others may decay at very different rates. Even among those enzymes in which 
the changes appear to be age related the mechanisms may be different. Changes in glucose 6-phosphate dehydrogenase with age appear to reflect a decrease in the amount of NADP bound. Measures which increase the amounts of NADP bound to the enzyme restore to the glucose 6-phosphate dehydrogenase of old erythrocytes the characteristics of young cells.

The erythrocytes of newborn infants carry out glycolysis more actively than those of adults, and they contain higher concentrations of adenine nucleotides $[16,19]$. We have found that they also contain higher concentrations of PRPP. The differences in PRPP concentration between the neonate and the adult are of the same order of magnitude as the differences in APRT activity. The changes in PRPP could explain the changes in APRT.

APRT activity is elevated in the erythrocytes of patients with the Lesch-Nyhan syndrome $[4,17,18$, 20]. The half-life of APRT in normal children is 34 days, whereas, in patients with the Lesch-Nyhan syndrome, it is 86 days [17]. Thus, when erythrocytes from these patients are fractionated according to age the greatest difference between patient and control occurs in the fractions containing the oldest cells. The APRT found in the erythrocytes of the patient with the Lesch-Nyhan syndrome is stabilized so that decay does not take place at the usual rate. There are various ways in which an altered biochemical environment can provide substrate, products, or other chemicals which can bind to an enzyme and protect it against inactivation [8]. Phosphoribosyl pyrophosphate has been shown to protect the APRT of murine tumor cells from inactivation by heat [13]. Increased concentrations of PRPP have been clemonstrated in erythrocytes of patients with the Lesch-Nyhan syndrome [7]. Human APRT purified from erythrocytes was found to be stabilized by PRPP against thermal inactivation [7]. Seegmiller and colleagues [7] interpreted these observations, and the fact that the erythrocytes of patients with the Lesch-Nyhan syndrome contained twice as much activity in the oldest $10 \%$ of their cells as in the control, to indicate that PRPP was responsible for a chemical stabilization of APRT against the in vivo attrition of enzyme that is a normal consequence of aging.

Elevated enzyme activity of APRT in the neonate could reflect an actual elevation in the amount of enzyme protein. This seems unlikely in view of the fact that similar activities could be demonstrated in the young cells of a population of erythrocytes from aclults. It is also possible that the metabolic environ- ment of erythrocytes from adults contains an inhibitor [9] not present in that from neonates. This is unlikely because the difference was also demonstrable after electrophoresis of the enzyme. Thus, any small molecule responsible for differences in activity would have to be firmly bound to the enzyme. This condition could be met by PRPP [6]. It seems likely, in view of the demonstration that there are increased concentrations of PRPP in the erythrocyte of the neonate, that the elevation of activity of APRT is due partly to a stabilization of the enzyme induced by PRPP. It is also partly due to the youth of the population of erythrocytes found in the neonate.

\section{Summary}

The activity of APRT was found to be elevated in the erythrocytes of normal newborn infants. The levels of activity obtained were almost twice those of normal aclults and approximated those found in patients with the Lesch-Nyhan syndrome. Fractionation of erythrocytes of adults into populations of young and old cells revealed significantly higher activity of APRT in the young cells. The concentration of PRPP was significantly higher in the erythrocytes of neonates than of adults. It was concluded that the elevated activity of APRT in the neonate reflected partly a young population of cells and partly a stabilization of APRT by PRPP against the inactivation of aging.

\section{References and Notes}

I. BAKAY, B.: Detection of radioactive components in polyacrylamicle gel disc electropherograms by automated mechanical fractionation. Anal. Biochem., f0: 429 (1971).

2. BAKAY, B., AND NYHAN, W. L.: The separation of adenine and hypoxanthine-guanine phosphoribosyl transferase isoenzymes by disc gel electrophoresis. Biochem. Genet., 5: 81 (1971).

3. Bakay, B., Nyhan, W. L., ANd Monkus, E. S. J.: Change in electrophoretic mobility of glucose 6-phosphoribosyl transferase with aging of erythrocytes. Pediat. Res., 6: 705 (1972).

4. Bakay, B., Telffer, M. A., AND Nyhan, W. L.: Assay of hypoxanthine-guanine and adenine phosphoribosyl transferases: A simple screening test for the Lesch-Nyhan syndrome and related disorders of purine metabolism. Biochem. Med., 3: 230 (1969).

5. Borun, R. R., Figueron, W. G., and Perry, S. M.: The clistribution of $\mathrm{Fe}^{50}$ tagged human erythrocytes in centrifuged specimens as a function of cell age. J. Clin. Invest., 36: 676 (1957).

6. GAdD, R. E. A., ANi Henderson, J. F.: Studies of the binding of phosphoribosyl pyrophosphate to adenine phosphoribosyltransferase. J. Biol. Chem., 245: 2979 (1970).

7. Greene, M. L., Boyle, J. A., And Seegmiller, J. E.: Substrate stabilization: Genctically controlled reciprocal relationship of two human enzymes. Science, 167: 887 (1970). 
8. GrISOLIA, S. L.: The catalytic environment and its biological implications. Physiol. Rev., 44: 657 (1964).

9. Henderson, J. F., Gadd, R. E. A., Palser, H. M., and Hori, M.: Mechanisms of inhibition of adenine phosphoribosyltransferase by adenine nucleosides and nucleotides. Can. J. Biochem., $48: 573$ (1970).

10. Kelley, W. N.: Hypoxanthine-guanine phosphoribosyltransferase deficiency in the Lesch-Nyhan syndrome and gout. Fed. Proc., 27: 1047 (1968).

11. Kogut, M. D., Donnell, G. N., Nyhan, W. L., and Sweetman, L.: Disorder of purine metabolism due to a partial deficiency of hypoxanthine guanine phosphoribosyl transferase. Amer. J. Med., 48 : 148 (1970).

12. Konrad, P. N., Valentine, W. N., and Paglia, D. E.: Enzymatic activities and glutathione content of erythrocytes in the newborn: comparison with red cells of older normal subjects and those with comparable reticulocytosis. Acta Haematol., 48: 193 (1972).

13. Murray, A. W., And Wong, P. C. L.: Stimulation of adenine phosphoribosyltransferase by adenosine triphosphate and other nucleoside triphosphates. Biochem. J., 104: 669 (1967).

14. Nyhan, W. L., James, J. A., Teberg, A. J., Sweetman, L., and Nelson, L. G.: A new disorder of purine metabolism with behavioral manifestations. J. Pediat., 74: 20 (1969).

15. Oski, F. A., And Naiman, J. L.: Hematologic Problems in the Newborn (W. B. Saunders, Inc., Philadelphia, 1966).

16. Oski, F. A., and Namian, J. L.: Red cell metabolism in the premature infant. I. Adenosinc triphosphate levels, adenosine triphosphate stability and glucose consumption. Pediatrics, 36: 104 (1965).

17. Ruisin, C. S., Balis, M. E., Piomelli, S., Berman, P. H., and DANcIs, J.: Elevated AMP pyrophosphorylase activity in congenital IMP pyrophosphorylase deficiency (Lesch-Nyhan diseasc). J. Lab. Clin. Med., 74: 732 (1969).

18. Seegmiller, J. E., Rosenbloom, F. M., and Kellfy, W. N.: Enzyme defect associated with a sex-linked human neurological disorder and excessive purine synthesis. Science, 155: 1682 (1967).

19. Stave, U., and Cara, J.: Adenosinphosphate im Blut Frühgeborenen: Hämatologische und enzymologische Studien im ersten Lebensjahr. $Z$. Kinderheilk, 86: 184 (196I).

20. SweEtman, L., and Nyhan, W. L.: Further studies of the enzyme composition of mutant cells in X-linked uric aciduria. Arch. Int. Med., 130: 214 (1972).

21. SWEeTMAN, L., AND NYHAN, W. L.: Quantitation of oxypurines and allopurinol metabolites in biological fluids by cationexchange chromatography. Anal. Biochem., 31: 358 (1969).

22. This work was supported by Grants no. HD-03015 from the National Institute of Child Health and Human Development and no. GMl1702 from the National Institute of General Medical Sciences, National Institutes of Health, United States Public Health Service.

23. Requests for reprints should be addressed to: William L. NYHAN, M.D., P. O. Box 109, University of California, San Dicgo, La Jolla, Calif. 92037.

24. Accepted for publication September 12, 1973. 